Check for updates

Cite this: RSC Adv., 2017, 7, 39237

\title{
Investigations on microwave deicing effects on graphite-modified concrete
}

\author{
Jun-liang Liu, (D) a Jin-yu $\mathrm{Xu}^{\mathrm{ab}}$ and Song Lu (D) a
}

The microwave deicing method is one of the non-contact deicing methods. As compared to the traditional deicing methods, microwave deicing method has a higher energy utilization ratio and a better deicing effect. Moreover, less influence on the environment is also an advantage of this method. In this study, $5 \%, 10 \%$, and $15 \%$ graphite was added to concrete as a wave absorbing material to modify the absorbing abilities of concrete. Then, the deicing efficiency of microwave towards the graphite-modified concrete (GMC) covered by an ice layer was investigated via analyzing the variations in the temperature-rising rate, ice layer destruction process, and effective deicing area. The results indicate that the addition of graphite obviously improves the microwave deicing efficiency. For the 15\% graphite addition, the temperature-rising rate is 2.5 times that of the plain concrete, and the effective deicing area is 2.2 times that of the plain concrete. The time when the effective deicing area appears reduces $40 \mathrm{~s}$ for the graphite addition of $15 \%$. Therefore, addition of graphite to concrete for modifying the microwave absorbing abilities of concrete is a feasible and effective way.

rsc.li/rsc-advances

\section{Introduction}

In some cold regions, road surfaces are always covered by snow or ice layers over a long period of time; this can lead to potential hazards to traffic safety. Some researches show that the friction coefficient of the icy road surface decreases by $70-80 \%$ as compared to that of the dry road surface; hence, this induces a $20 \%$ increase in the traffic accident rate..$^{1,2}$ Therefore, it is important to quickly and efficiently remove the ice layers to reduce their adverse effects on traffic. The traditional methods used for deicing includes manual deicing, mechanical deicing, thermal deicing, and chemical deicing. ${ }^{3}$ The manual deicing method is time-consuming, and its deicing effect is unsatisfactory. The mechanical deicing method is also inefficient, and the pavements are easy to be scratched or destructed by the ice breakers used. The thermal deicing method consumes plenty of heat energy or electric energy, whereas the actual utilization ratio of the energy is limited. ${ }^{4}$ The chemical deicing method, such as use of a deicing salt or deicing agent, can make a serious corrosion to the road surface and vehicle parts., ${ }^{5,6}$ From the abovementioned statements, it can be seen that the traditional deicing methods still have many disadvantages. The efficiency and applicability of these methods need to be further improved.

Microwave deicing is a new deicing method that uses microwave heating. As compared to the traditional deicing

${ }^{a}$ Department of Airfield and Building Engineering, Air Force Engineering University, Xi'an 710038, Shaanxi, China.E-mail: liujunliangafeu@163.com; lusong647@163. com

${ }^{b}$ College of Mechanics and Civil Architecture, Northwest Polytechnic University, Xi'an 710072, Shaanxi, China. E-mail: xujinyukgd@163.com methods, microwave deicing has a higher energy utilization ratio and a better deicing effect. Moreover, less influence on the environment is also an advantage of this method. ${ }^{7}$ Several typical researches on microwave deicing are as follows. Wuori ${ }^{8}$ explored new techniques for removing ice. The results show that the use of microwave radiation to remove ice is feasible. Wang et al. ${ }^{9}$ investigated the influences of carbon fiber at different contents on the mechanical properties, microwave reflectivity, and microwave deicing time of asphalt mixtures. The results indicate the percentage of carbon fiber has significant influences on the mechanical properties and deicing performances of asphalt mixtures. Guan et al. ${ }^{10}$ applied microwave heating technology to remove ice. The results indicate that ice does not absorb microwave energy, and the road materials can largely absorb microwave energy. The authors also designed an ice removing vehicle that applies the microwave energy to remove ice. Jiao et al. ${ }^{11-15}$ simulated a microwave deicing procedure via a three-dimensional model. The results show that the environmental temperature, ice thickness, and impurity content of ice influence the microwave deicing efficiency of the road materials. In brief, improving the microwave absorption rate of the pavement is a key factor that influences the efficiency of the microwave deicing method. The modification of the pavement material via the addition of some wave absorbing materials is an effective way to realize this purpose.

The wave absorbing materials are characterized by their electromagnetic loss properties via which the electromagnetic waves can be efficiently absorbed and then converted into heat energy. ${ }^{16}$ The conventional wave absorbing materials include graphite, iron oxide black, carbon fiber, etc. In this study, 
graphite was added to the concrete as a wave absorbing material. Then, the deicing efficiency of the microwave towards the graphite-modified concrete (GMC) covered by the ice layer was investigated via analyzing the variations in the temperaturerising rate, ice layer destruction process, and effective deicing area. Finally, the mechanism of the deicing efficiency enhancement caused by the addition of graphite has been discussed.

\section{Experiments}

\subsection{Materials and specimen preparation}

Binder materials used in the production of GMC include Portland cement with $42.5 \mathrm{R}$ conforms to Chinese standard, limestone with a density of $2.71 \mathrm{~g} \mathrm{~cm}^{-3}$, and river sand with a density of $2.57 \mathrm{~g} \mathrm{~cm}^{-3}$. Limestone with a particle size of 5-40 $\mathrm{mm}$ was used as coarse aggregates. Polycarboxylate superplasticizer with a water reducing ratio of $30 \%$ was used to improve the workability of freshly mixed concrete. Graphite with a purity level over $99.0 \%$ was adopted to improve the microwave absorbing ability of concrete.

Herein, four series of GMC specimens with the graphite mass fraction of $0 \%, 5 \%, 10 \%$, and $15 \%$ were produced and labeled as GMC0, GMC5, GMC10, and GMC15, respectively. Table 1 lists the corresponding mix proportions. The addition ratio of graphite was selected based on the results reported in ref. 17; it was observed that the cement with $15 \%$ graphite addition could achieve the best microwave absorbing ability. Moreover, the workability and strength of GMC were also considered to determine the addition ratio of graphite.

A forced mixer was used to mix the raw materials of GMC. The mixing procedure was designed as follows. First, river sand and coarse aggregates were mixed for $60 \mathrm{~s}$. Then, cement and graphite were added to the mixer and mixed for $60 \mathrm{~s}$. At last, the water-superplasticizer mixture was poured into the mixer and mixed for $120 \mathrm{~s}$. After mixing, mixtures were cast into cubic and cuboid moulds, and the specimens were demoulded after $24 \mathrm{~h}$ curing at room temperature. Then, the specimens were stored in a standard room at a temperature of $20 \pm 2{ }^{\circ} \mathrm{C}$ for additional 28 days. The side lengths of the cubic specimen were $150 \mathrm{~mm}$ and $100 \mathrm{~mm}$. The specimens with $150 \mathrm{~mm}$ side lengths were used for microwave deicing test, and the specimens with 100 $\mathrm{mm}$ side lengths were used for the compressive test. The cuboid specimens with the dimensions $100 \times 100 \times 400 \mathrm{~mm}$ were used for the flexural test.

The procedure to make an ice layer covering on the cubic specimen $(150 \times 150 \times 150 \mathrm{~mm})$ was as follows. First, a plastic bag was used to wrap the specimen. Then, a paper shell was fixed around the specimen (see Fig. 1). After this, water was poured into the plastic bag, and the height of the water was controlled by a ruler. At last, the specimen was put in a freezer.

\subsection{Experimental methods}

Compressive tests and flexural tests for GMC specimens were performed via a servohydraulic testing machine with the loading rate of $0.5 \mathrm{MPa} \mathrm{s}^{-1}$.

WZP-128 thermal resistance (see Fig. 2) was adopted to measure the temperature on the specimen surface. The measured range of resistance is from $-30{ }^{\circ} \mathrm{C}$ to $250{ }^{\circ} \mathrm{C}$, and the accuracy of temperature measurement is $0.1{ }^{\circ} \mathrm{C}$. A MEACON multi-channel recorder was used to obtain the temperature data from thermal resistances every second. Data of 12 thermal resistances were obtained at the same time.

A self-made microwave transmitter (see Fig. 3) was used as the microwave source. The microwave transmitter consisted of a magnetron, water cooling device, height adjusting device, and external control box. Herein, five levels of microwave source height of $20 \mathrm{~mm}, 30 \mathrm{~mm}, 50 \mathrm{~mm}, 70 \mathrm{~mm}$, and $100 \mathrm{~mm}$ were conducted by adjusting the waveguide height to test the microwave deicing efficiency of GMC under different waveguide heights.

\section{Principles of the microwave deicing method}

Polar molecules in the material will create polarization phenomenon in the microwave field. The friction between polar molecules will produce a lot of heat energy due to the gyrate and concuss of polar molecules.

The dissipation of microwave energy can be expressed as follow: ${ }^{18}$

$$
P=0.556 f E^{2} \varepsilon_{\mathrm{r}}^{\prime} \tan \delta \times 10^{-12}
$$

where $P$ denotes the dissipation power of microwave energy in a material; $f$ and $\tan \delta$ are microwave frequency and dielectric loss angle constant of concrete, respectively.

It can be seen from the eqn (1) that the relative permittivity and dielectric loss angle constant have great influences on the microwave absorbing ability of the material. Table 2 lists the relative permittivity and dielectric loss angle constant of concrete. According to Table 2, relative permittivity of ice at a low level leads to a lower microwave absorbing ability. Moreover, the relative permittivity of concrete ranges from 6 to 20 ,

Table 1 Mix proportions of GMC $\left(\mathrm{kg} \mathrm{m}^{-3}\right)$

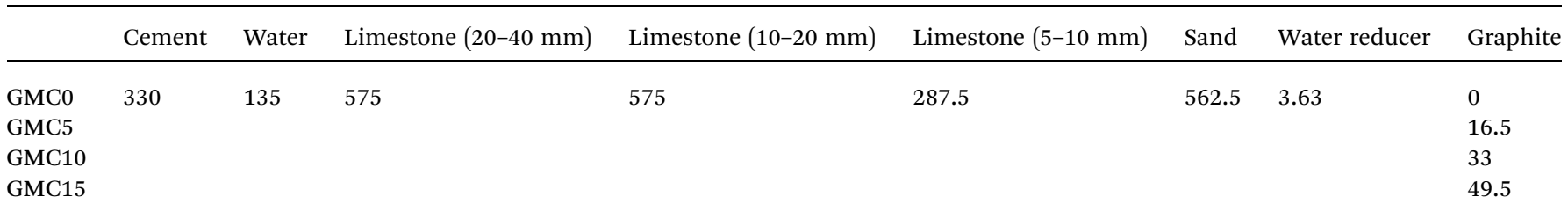




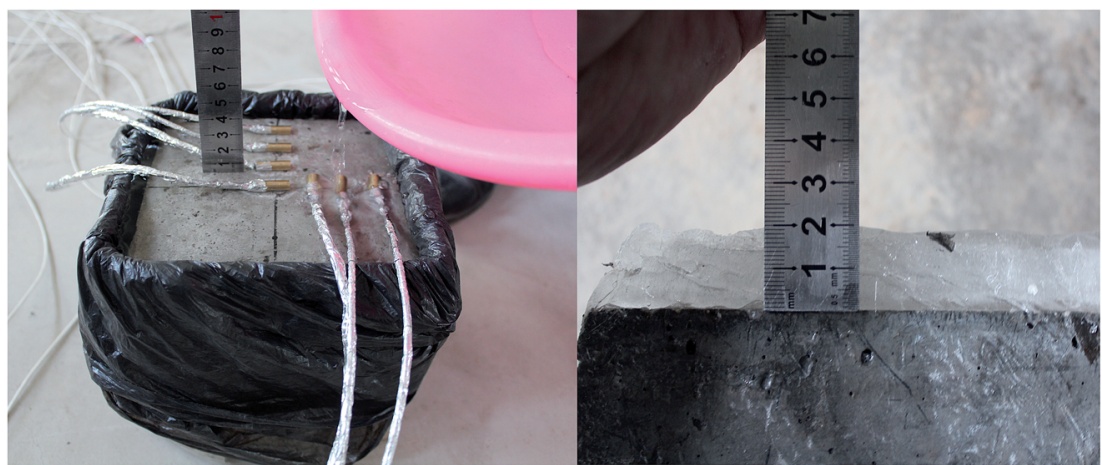

Fig. 1 Frozen and control of ice layer on specimen.

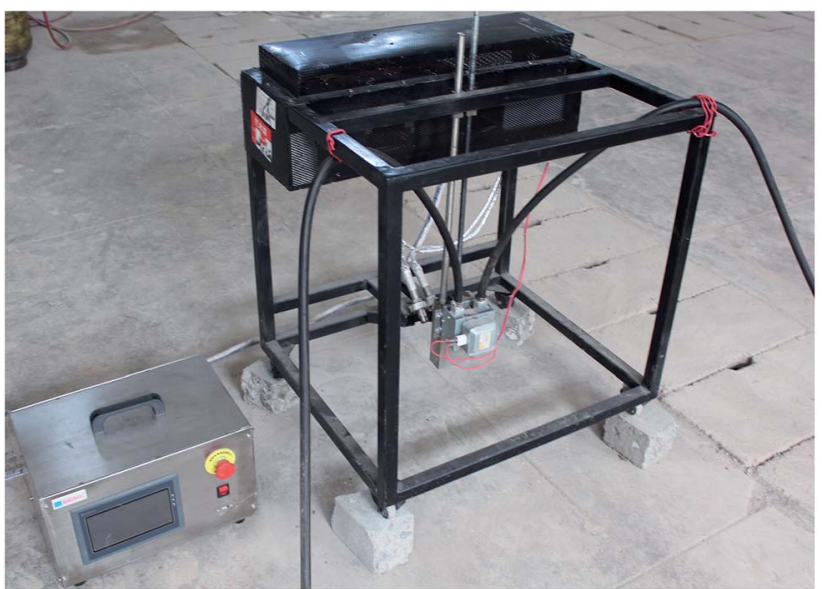

Fig. 2 Microwave system.

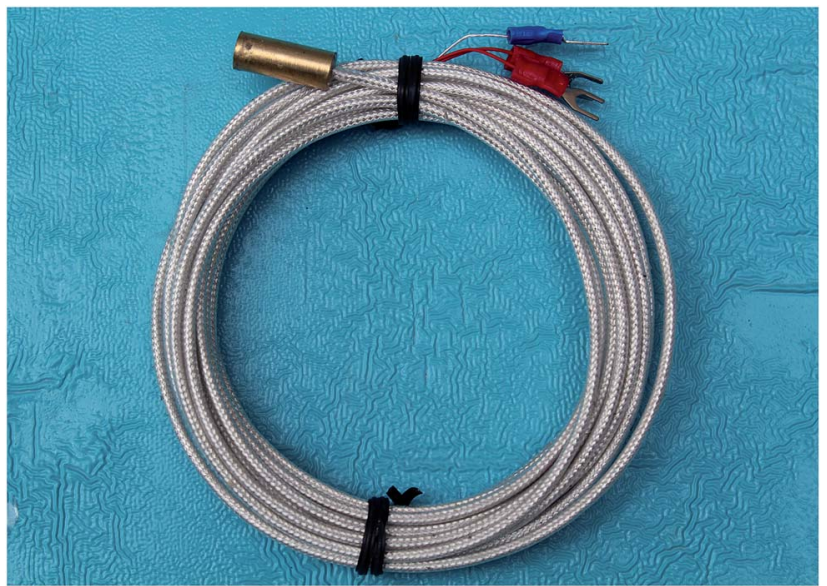

Fig. 3 WZP-128 thermal resistance.

and it is much higher than the relative permittivity of ice. Therefore, concrete will absorb more microwave energy than the ice layer in the microwave field. As a result, concrete can convert microwave energy into heat. Then, the heat melts the ice layer on the concrete surface. In general, different microwave absorbing abilities of concrete and ice layer are the key points for the microwave deicing method. ${ }^{19}$
Table 2 Relative permittivity of concrete materials

\begin{tabular}{llll}
\hline Materials & Temperature $\left({ }^{\circ} \mathrm{C}\right)$ & $\varepsilon^{\prime}{ }_{\mathrm{r}}$ & $\tan \delta$ \\
\hline Water & 20 & 76.7 & 0.157 \\
Ice & -12 & 3.2 & 0.0009 \\
Asphalt concrete & 20 & $4.5-6.5$ & $0.015-0.036$ \\
Cement concrete & 25 & $6-20$ & 0.06
\end{tabular}

\section{Results and discussion}

\subsection{Mechanical properties analysis}

Fig. 4(a) and (b) display the compressive strength and flexural strength of GMC. It can be seen that both compressive and flexural strength of GMC sharply decrease with an increase in the addition of graphite. For example, the compressive and flexural strength of GMC15 are 28.3 MPa and 4.9 MPa, which are only $58 \%$ and $82 \%$ those of GMC0. Although the mechanical properties of GMC decrease, it still satisfies to the road standard. The decrease in the mechanical properties of GMC is due to the weakness caused by graphite since graphite does not participate in the cement hydration reactions. Therefore, the weakness caused by graphite in concrete results in cracks under the applied loads. These cracks accelerate the damage of concrete and cause a reduction in the mechanical properties of the concrete.

The Vebe consistency of GMC0, GMC5, GMC10, and GMC15 binder is $22 \mathrm{~s}, 26 \mathrm{~s}, 31 \mathrm{~s}$, and $40 \mathrm{~s}$, respectively. The increase of Vebe consistency becomes obvious with the increase in graphite addition. Graphite added in concrete occupies a larger volume, and graphite costs a large amount of cement paste. The cement paste then becomes thick, and the concrete slump decreases.

\subsection{Temperature-rising rate analysis}

Fig. 5 displays the temperature-time curves for the surface of the GMC specimens. As shown in Fig. 5, the temperature-time curves of GMC show a linear upward tendency with time. Change in graphite addition does not influence the tendency of the temperature-time curves. Moreover, graphite added in concrete obviously improves the temperature-rising rate. During the microwave heating time of $80 \mathrm{~s}$, the temperature- 
(a)

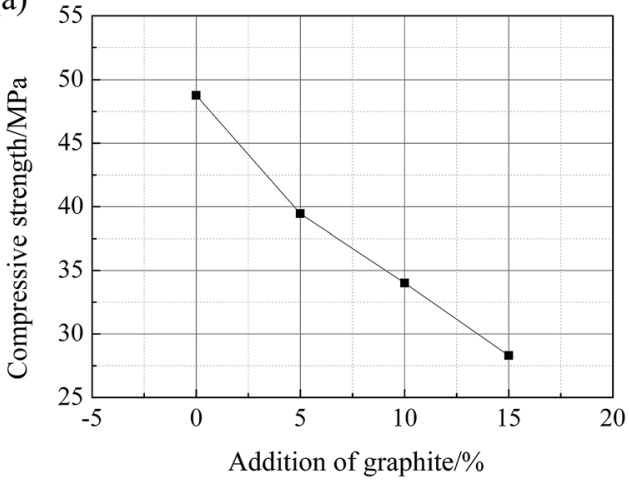

(b)

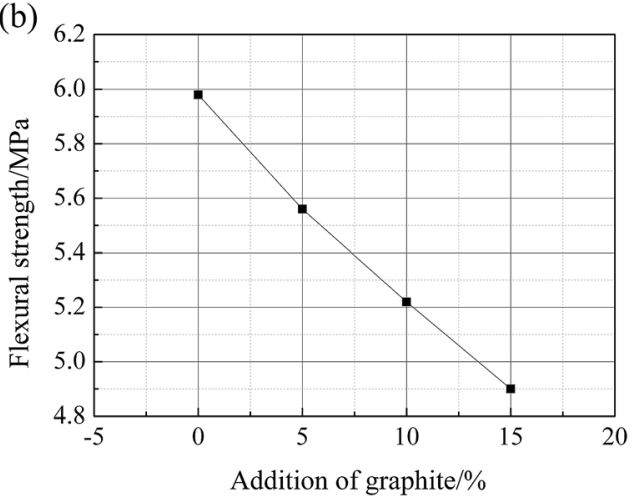

Fig. 4 Compressive strength and flexural strength of GMC.

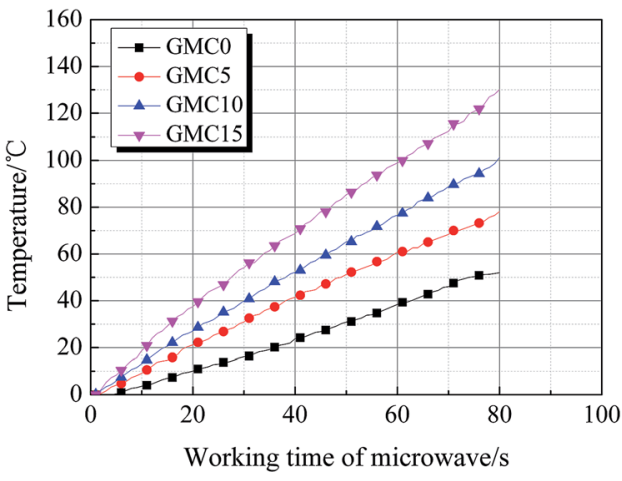

Fig. 5 Temperature-time curve of GMC.

rising rates of GMC0, GMC5, GMC10, and GMC15 are 0.6513, $0.9763,1.2625$, and $1.6264{ }^{\circ} \mathrm{C} \mathrm{s}^{-1}$, respectively. The temperature-rising rate of GMC15 is 2.5 times that of GMC0.

Fig. 6 shows the temperature-rising rate of GMC under different microwave source heights during the microwave deicing periods. It can be seen from Fig. 6 that the temperaturerising rate of GMC sharply decreases with the increase of microwave source height. As for GMC15, the temperature-rising rate is $1.6264{ }^{\circ} \mathrm{C} \mathrm{s}^{-1}$ at the microwave source height of $20 \mathrm{~mm}$, and the temperature-rising rate decreases to $0.2887^{\circ} \mathrm{C} \mathrm{s}^{-1}$ when the microwave source height is $100 \mathrm{~mm}$. Moreover, the influences of graphite on the temperature-rising rate decrease with

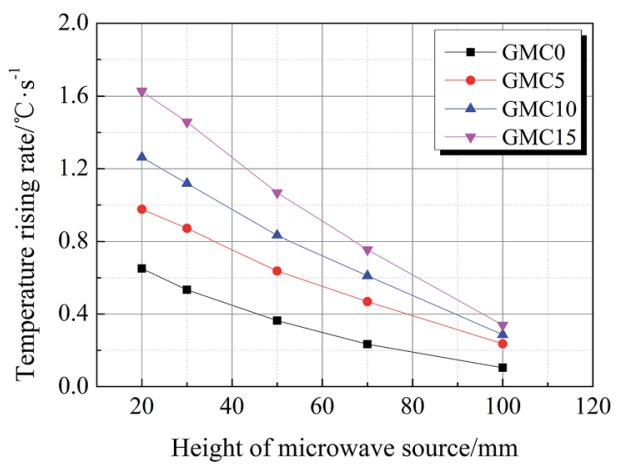

Fig. 6 Temperature-rising rate of GMC. the increase in the microwave source height. For example, when the graphite addition is increased to $5 \%$, the temperature-rising rate at the microwave height of $20 \mathrm{~mm}$ increases to $0.313^{\circ} \mathrm{C} \mathrm{s}^{-1}$, whereas the temperature-rising rate only increases to $0.0625{ }^{\circ} \mathrm{C} \mathrm{s}^{-1}$ when the microwave source height is $100 \mathrm{~mm}$. The results show that the height of the microwave source has great influence on the microwave heating effects, which agrees with the findings reported in ref. 13 and 15.

\subsection{Ice layer destruction process analysis}

The ice layer destruction process is studied to determine the microwave deicing efficiency of GMC. Fig. 7 shows the ice layer destruction process of GMC0. From Fig. 7, it can be seen that (1) the ice layer on the GMC0 surface has not changed over 0-70 s. The ice layer is difficult to be broken during this time; (2) the ice layer starts to melt when the microwave heating time reaches $90 \mathrm{~s}$. The ice layer is broken easily in the melted area; and (3) the melted area of ice layer increases with the increase of microwave heating time. At the microwave heating time of $160 \mathrm{~s}$, the ice layer above the concrete center point completely melted. The ice layer destruction process shows that the ice layer could be easily broken at higher temperatures. When the temperature on the concrete surface is greater than $0{ }^{\circ} \mathrm{C}$, the bond stress between the ice and concrete approaches $0 \mathrm{kN}$. Then, the ice layer can be easily and completely removed, which agrees with the findings reported in ref. 13. However, when the temperature on the concrete surface is less than $0{ }^{\circ} \mathrm{C}$, the ice layer is broken with difficultly due to the strong bond stress between the ice and concrete. This viewpoint is also supported by the results reported in ref. 20.

Fig. 8 shows the ice layer destruction process of GMC15. As shown in Fig. 8, the melting rate of the ice layer displays an obvious improvement. For instance, the ice layer of GMC15 started to melt at the microwave heating time of $50 \mathrm{~s}$, whereas the ice layer of GMC0 started to melt at the microwave heating time of $70 \mathrm{~s}$. When the microwave heating time reached $130 \mathrm{~s}$, the ice layer of GMC15 melted into water, and water started to flow from the sides of the specimen. At this moment, the deicing area extended to the brinks of the specimen.

The ice layer destruction process shows that the addition of graphite obviously improves the microwave deicing efficiency. 

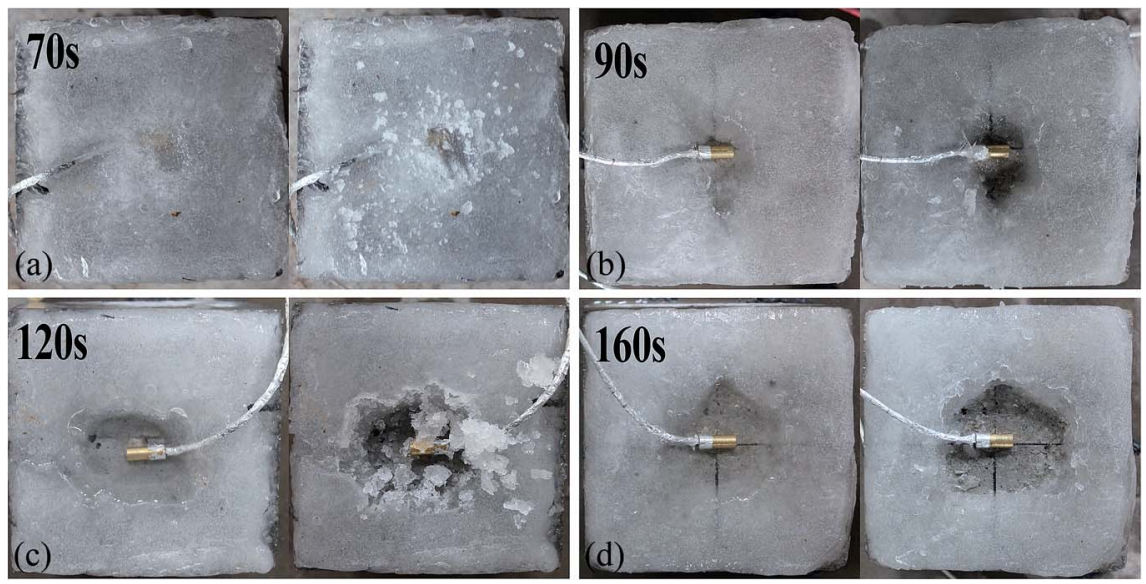

Fig. 7 Ice state and de-icing effect in different microwave working time.
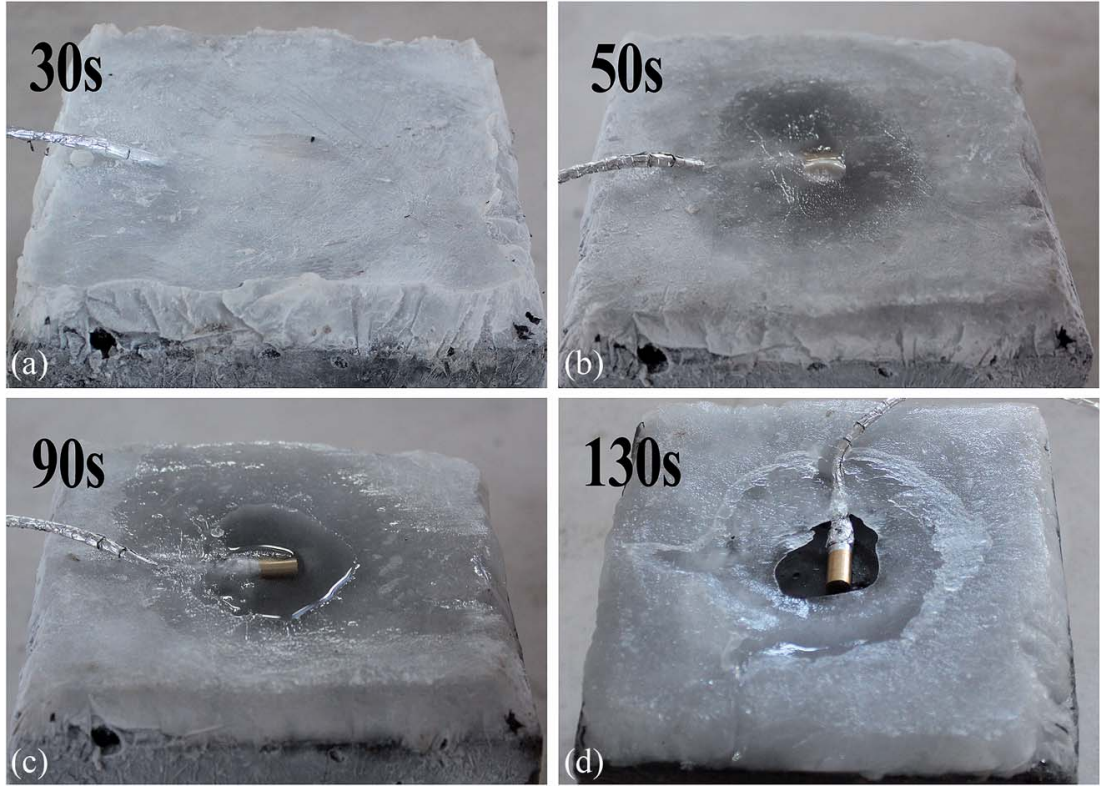

Fig. 8 Microwave de-icing effect of GMC15.

Xie et al. ${ }^{21}$ investigated the deicing characters of infrared ray deicing, and the results indicated that $1002 \mathrm{~s}$ was required for infrared ray to melt ice. The authors also studied the deicing efficiency of hot air deicing method. ${ }^{22}$ The results show that 22 minutes was required to melt ice using $50{ }^{\circ} \mathrm{C}$ hot air. Enríquez et $a l^{23}$ studied the electrical deicing properties of carbon black-silica coatings, and the results indicate that this method requires 6-8 minutes to melt ice. It can be found from the researches that the microwave deicing method has a higher efficiency to melt ice, and the addition of graphite obviously improves the microwave deicing efficiency.

\subsection{Effective deicing area analysis}

The temperature of the contact area between the concrete and ice layer plays an important role in the ice layer destruction. For the temperature of $0{ }^{\circ} \mathrm{C}$, the ice layer can be easily broken and removed. Therefore, the area compassed by isotherm at $0{ }^{\circ} \mathrm{C}$ on the concrete surface can be defined as the effective deicing area during the microwave deicing. An approximate calculation of the effective deicing area was conducted because the isotherm at $0{ }^{\circ} \mathrm{C}$ could not be accurately measured. In the approximate calculation of the effective deicing area, temperatures of thermal resistances on $x$-axis and $y$-axis were used to approximately calculate the $0{ }^{\circ} \mathrm{C}$ point on the $x$-axis and $y$-axis. Rhombus area (see Fig. 9) composed of $0{ }^{\circ} \mathrm{C}$ points on the $x$-axis and $y$-axis was calculated as the effective deicing area.

Fig. 10 displays the effective deicing areas of GMC0 and GMC15 at the microwave source height of $20 \mathrm{~mm}$. It can be seen from Fig. 10 that the graphite addition obviously improves the effective deicing area. The effective deicing area of GMC15 appears after $30 \mathrm{~s}$ of microwave deicing, whereas the effective deicing area of GMC0 appears after $70 \mathrm{~s}$ of microwave deicing. 


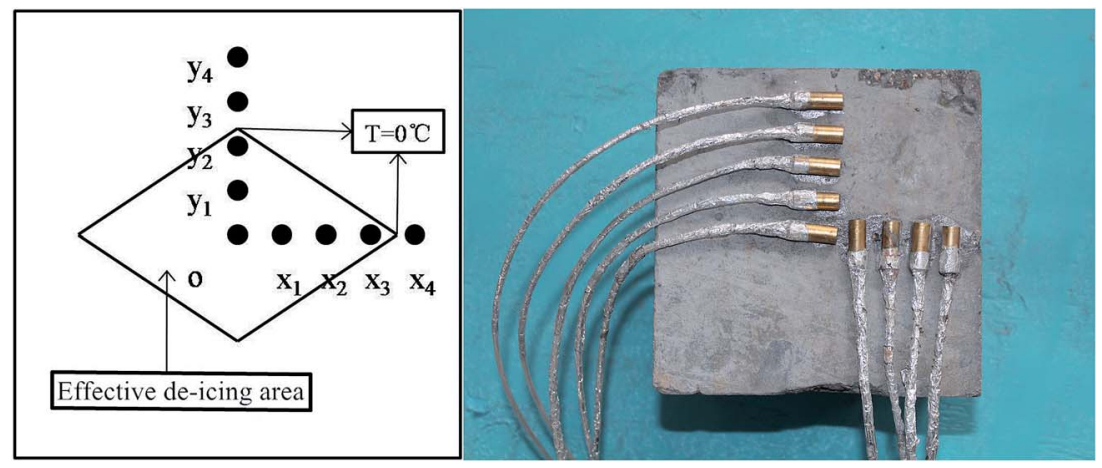

Fig. 9 Approximate calculation of effective de-icing area.

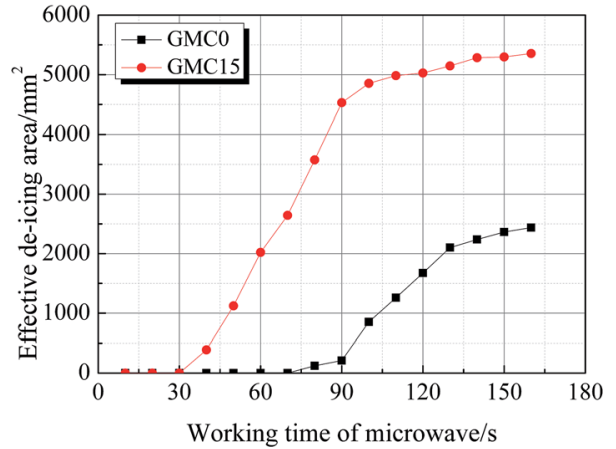

Fig. 10 Comparison between the effective de-icing area of GMC15 and GMCO.

Moreover, the effective deicing area of GMC0 is $2437.5 \mathrm{~mm}^{2}$, whereas that of GMC15 is $5355.4 \mathrm{~mm}^{2}$.

Fig. 11 shows the influences of graphite addition on the compressive strength, flexural strength, and temperature rising rate. It can be seen from Fig. 11 that the temperature rising rate is more obviously influenced than the strength properties.

\subsection{Mechanism analysis}

Graphite has a small density and large specific surface. These factors are important to improve the microwave absorbing abilities of concrete, but they also have a negative effect on the

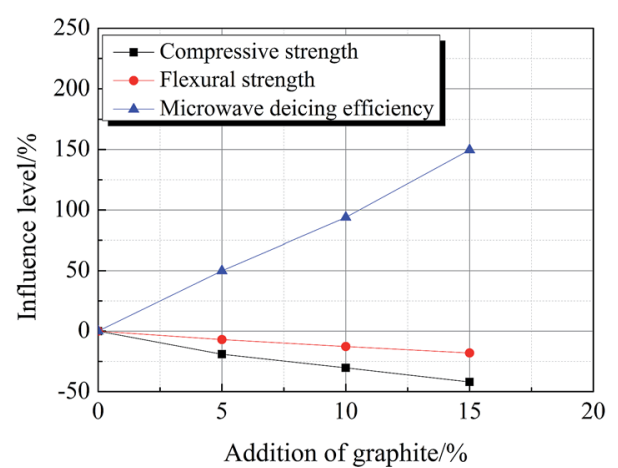

Fig. 11 The influence level of graphite on different properties of concrete. mechanical properties of concrete. The addition of graphite increases the cost of cement paste such that the cement paste becomes thicker and the concrete slump decreases. The graphite will not participate in the hydration reaction of cement; this can further lead to the formation of the weaknesses in the GMC specimens. These weaknesses further grow into cracks under applied loading, which accelerates the destruction of the specimen and also causes the strength loss.

A developed electric conductive network in GMC was formed due to the great conductivity of graphite. Therefore, GMC has the following characters in the microwave filed. ${ }^{24,25}$ (1) Heat energy is created by the electric current due to the addition of graphite, which forms a local and integral conductive network in the concrete. In the microwave field, the graphite particles in GMC are polarized, and the polarization of the particles lag behind the electric field. Then, the eddy current is generated in the GMC. The eddy current converts the microwave energy into heat energy due to the electric resistance of GMC. (2) Graphite has a small particle size and a large specific surface. These particles scatter and reflect microwave such that the microwave energy can be rapidly consumed and converted into heat energy.

\section{Conclusions}

In this study, graphite was added to concrete to modify the microwave absorbing ability of concrete. Then, the deicing efficiency of the microwave towards the GMC covered by the ice layer was investigated by analyzing the variations in the temperature-rising rate. Based on the studies of the ice layer destruction process, the effective deicing area was defined as the area with a higher temperature than $0{ }^{\circ} \mathrm{C}$ on the concrete surface. At last, the mechanism of the deicing efficiency enhancement caused by the graphite addition in concrete has been discussed.

The results show that the addition of graphite greatly improves the microwave deicing efficiency. The temperature rising rate of GMC15 is 2.5 times that of GMC0. The ice layer could be broken easily when the temperature on the concrete surface was higher than $0{ }^{\circ} \mathrm{C}$. In addition, the effective deicing area of GMC15 is 2.2 times that of GMC0. The time when the effective deicing appears reduces $40 \mathrm{~s}$ for GMC15. The influence 
of graphite on microwave deicing efficiency is more obvious than that on the compressive strength, flexural strength, and Vebe consistency.

Graphite modifies the microwave absorbing abilities of concrete, but it also weakens the mechanical properties. Moreover, there are several microwave absorbing materials such as iron oxide black, carbon fiber, etc. In future research, more attentions should be paid to the influence of mixed absorbing materials on the microwave deicing efficiency to make the concrete maintain the well microwave deicing efficiency as well as satisfy the strength properties.

\section{Conflicts of interest}

There are no conflicts to declare.

\section{Acknowledgements}

The authors would like to acknowledge the projects of the National Natural Science Foundation of China [grant number 51208507, 51378497].

\section{References}

1 B. Liu, K. Zhang, C. Tao, et al., Strategies for anti-icing: low surface energy or liquid-infused?[J], RSC Adv., 2016, 6(74), 70251-70260.

2 A. Muthumani, L. Fay, M. Akin, et al., Correlating lab and field tests for evaluation of deicing and anti-icing chemicals: A review of potential approaches[J], Cold Reg. Sci. Technol., 2014, 97, 21-32.

3 Y. Yu, Development and prospect of pavement active ice (snow) melting technology[J], J. Shanghai Jiaotong Univ., 2011, (S1), 86-89.

4 F. Yang, Research on carbon fiber heating wire for pavement deicing, Chang'an University, Xi'an, 2014.

5 J. F. Young, The Science and technology of civil engineering materials[M], Prentice Hall, 1998.

6 Q. Yang, Effects of salt and snow-thawing agent types on saltscaling damage of concrete[J], J. Build. Mater., 2006, 9(4), 464-467.

7 D. P. Lindroth, W. R. Berglund and C. F. Wingquist, Microwave thawing of frozen soils and gravels $[\mathrm{J}], \mathrm{J}$. Cold Reg. Eng., 1995, 9(2), 53-63.

8 A. F. Wuori, Ice-pavement bond disbonding: Surface modification and disbonding[R], Strategic Highway Research Program, National Research Council, 1993.

9 Z. Wang, H. Wang, D. An, et al., Laboratory investigation on deicing characteristics of asphalt mixtures using magnetite aggregate as microwave-absorbing materials[J], Constr. Build. Mater., 2016, 124, 589-597.

10 M. Guan, Y. Xu, T. Lu, et al., Application of microwave heating on removing ice on streets[J], J. Northern Jiaotong Univ., 2003, 27(4), 79-83.

11 S. Jiao, X. Tang, Z. Gao, et al., Study of key technology on microwave deicing efficiency[J], China J. Highw. Transp., 2008, 21(6), 121-126.

12 X. Tang, S. Jiao, Z. Gao, et al., Application and analysis of microwave deicing[J], Road Machinery \& Construction, 2008, 25(7), 15-18.

13 X. Tang, Study of microwave deicing efficiency on road, Chang'an University, Xi'an, 2009.

$14 \mathrm{~W}$. Chen, Simulation research for on-site microwave heating of asphalt pavement, Chang'an University, Xi'an, 2009.

$15 \mathrm{X} . \mathrm{Xu}$, The simulation of $5.8 \mathrm{GHz}$ microwave road deicing's temperature field based on the theory of electromagnetic coupling hot, Chang'an University, Xi'an, 2009.

16 S. Liu, J. Liu and X. Dong, Electromagnetic wave shielding and absorbing material[M], Chemical Industry Press, 2007.

17 X. Jia, Y. Zhang, J. Qian, et al., Microwave absorbing property of the graphite foam concrete [J], J. Funct. Mater., 2012, 17, 031.

$18 \mathrm{~S} . \mathrm{Lu}, \mathrm{J} . \mathrm{Xu}, \mathrm{E}$. Bai, et al., Investigating microwave deicing efficiency in concrete pavement[J], RSC Adv., 2017, 7(15), 9152-9159.

19 Z. Wu, B. Deng, J. Liu, et al., Highly efficient microwave heating for target area based on metamaterial[J], Microw. Opt. Technol. Lett., 2017, 59(4), 758-761.

20 H. C. Dan, L. H. He, J. F. Zou, et al., Laboratory study on the adhesive properties of ice to the asphalt pavement of highway[J], Cold Reg. Sci. Technol., 2014, 104, 7-13.

21 T. Xie, J. Dong, H. Chen, et al., Experiment investigation on deicing characteristics and energy efficiency using infrared ray as heat source[J], Energy, 2016, 116, 998-1005.

22 T. Xie, J. Dong, H. Chen, et al., Experimental investigation of deicing characteristics using hot air as heat source[J], Appl. Therm. Eng., 2016, 107, 681-688.

23 E. Enríquez, J. F. Fernández, J. De Frutos, et al., Tailoring of the electrical properties of carbon black-silica coatings for de-icing applications[J], Ceram. Int., 2015, 41(2), 2735-2743.

$24 \mathrm{~J}$. Xin and X. Jia, Effect of Graphite on the Microwave Susceptibility of Cement Foam Concrete[J], J. Microwave Power, 2015, 49(4), 256-263.

25 W. Meng, D. Yuping, L. Shunhua, et al., Absorption properties of carbonyl-iron/carbon black double-layer microwave absorbers[J], J. Magn. Magn. Mater., 2009, 321(20), 3442-3446. 